\title{
La OEI y la Universidad de Alicante forman en cultura digital y propiedad intelectual a los profesionales culturales iberoamericanos
}

Con el fin de concienciar sobre la cultura digital y los derechos de propiedad intelectual, la Organización de Estados Iberoamericanos para la Educación la Ciencia y la Cultura (OEI) y la Universidad de Alicante, a través de su Cátedra Iberoamericana de Cultura Digital y Propiedad Intelectual, impartieron el Seminario online de cultura digital y propiedad intelectual: retos y oportunidades, (protección de derechos de autor en el contexto digital). La formación, que se impartió a lo largo de siete sesiones online entre los meses de junio y octubre de 2021, se ofertó como seminario para un grupo de 50 trabajadores culturales y como ciclo de conferencias en abierto.

Cristina Ortiz Portillo | Organización de Estados Iberoamericanos para la Educación, la Ciencia y la Cultura (OEI)

URL de la contribución <http://www.iaph.es/revistaph/index.php/revistaph/article/view/5054>

La fuerte digitalización, que se aceleró con el inicio de la pandemia del COVID-19, influyó claramente en el sector cultural que vio aumentadas sus posibilidades para difundir y diseminar contenidos así como comercializar servicios y productos culturales. No obstante, la revolución digital también supuso y supone un desafío y una amenaza para la conservación y preservación del patrimonio cultural, así como para la garantía de los derechos culturales, el acceso a la cultura, el ámbito laboral y el derecho de propiedad intelectual.

En el ámbito de la cultura los adelantos en cuanto a la digitalización tienen un impacto directo en materia de propiedad intelectual, aunque, de un mismo modo, posibilitan nuevas prácticas y modelos aplicables a la gestión, protección del patrimonio y digitalización de bibliotecas y museos entre otros.

Nos encontramos en un contexto en el que la cultura digital iberoamericana está en auge. Según datos del Instituto Cervantes (Instituto Cervantes 2021), el español es la tercera lengua más utilizada en Internet (con un total de 7,9\% de usuarios comunicándose en este idioma); y según Albuquerque y Esperança (2010) el portugués es la quinta lengua con mayor número de países de lengua oficial. Por tanto, resulta esencial fortale- cer la protección al derecho tanto desde la oferta como desde la demanda cultural.

\section{La Carta Cultural Iberoamericana: un documento clave para los derechos culturales}

En el ámbito iberoamericano, los derechos culturales vienen recogidos en la Carta Cultural Iberoamericana, aprobada en la XVI Cumbre Iberoamericana de Jefes de Estado y de Gobierno celebrada en 2006 en la ciudad de Montevideo. El documento pionero, que cumplió quince años en noviembre de 2021, reconoce también el derecho de propiedad intelectual para mejorar las condiciones laborales de los trabajadores de la cultura en el contexto digital. En este sentido, la Carta Cultural Iberoamericana también considera el derecho a la propiedad intelectual un factor esencial para el acceso, la creación, producción y circulación de contenidos culturales en Iberoamérica.

La Carta Cultural Iberoamericana es también el documento a partir del cual la Organización de Estados Iberoamericanos (OEI) define sus acciones y líneas estratégicas en materia de cultura, como son la generación de conocimiento, favoreciendo el intercambio de experiencias en el ámbito de los derechos culturales y del fomento de la diversidad cultural. 


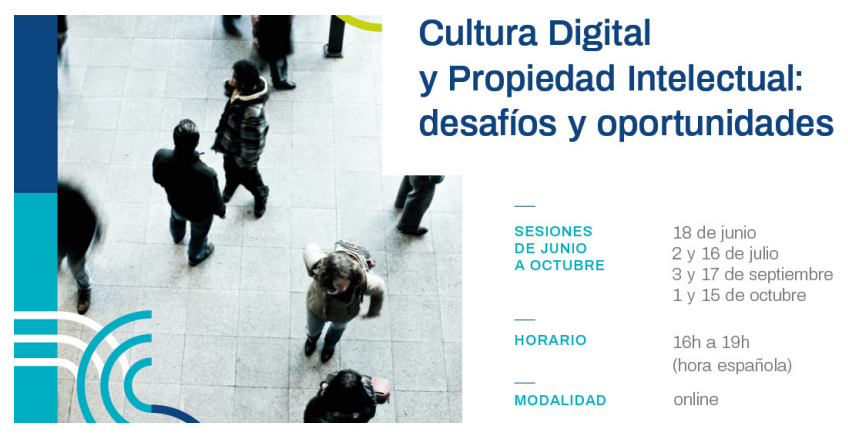

En ese sentido y con el fin acompañar y facilitar los retos que plantea la cultura digital iberoamericana, desde la perspectiva de los derechos culturales, la OEI y la Universidad de Alicante crearon en 2020 la Cátedra Iberoamericana de Cultura Digital y Propiedad Intelectual.

\section{Formar en cultura digital y propiedad intelectual para} proteger las expresiones culturales de Iberoamérica La Cátedra nació como un espacio de conocimiento y trabajo compartido para contribuir al equilibrio de derechos culturales en Iberoamérica, la transferencia de conocimiento y el apoyo a las industrias culturales y creativas, desde una perspectiva digital en todos sus ámbitos de acción. Entre las distintas líneas de acción de la Cátedra destacan la generación de conocimiento, la oferta de becas y la formación.

En este último eje se encuentra enmarcado el Seminario online de cultura digital y propiedad intelectual: retos y oportunidades, (protección de derechos de autor en el contexto digital). Se creó con el objetivo de concienciar sobre los derechos de propiedad intelectual con especial hincapié en la protección de las expresiones culturales, el fortalecimiento de las capacidades de gestión y protección de la cultura digital y la identificación de buenas prácticas dedicadas a preservar y divulgar la diversidad y las expresiones culturales en el entorno digital.

El seminario se impartió entre los meses de junio y octubre de 2021 en dos modalidades: como seminario para un grupo de 50 trabajadores culturales y de las oficinas de propiedad intelectual de los organismos públicos de los Estados miembros de la OEl; y como ciclo de conferencias, en abierto, a las que se registraron más de 300 personas, especialmente estudiantes y profesionales del sector interesados.

A lo largo de las siete sesiones el profesorado profundizó en cultura digital y propiedad intelectual; propiedad intelectual y acceso al conocimiento; políticas de ciencia abierta; digitalización, preservación y acceso al patrimonio cultural de Iberoamérica; el rol de las plataformas electrónicas en la divulgación y protección de las producciones culturales en el entorno digital y, por último, la gestión de derechos de propiedad intelectual en el entorno de la cultura digital en las artes escénicas, del sector audiovisual, del sector del libro y de la música.

El profesorado estuvo formado por profesionales y expertos en las distintas áreas de formación, de instituciones como la Universidad de Alicante; el Ministerio de Cultura y Deporte de España; la Universitat Oberta de Cataluña; la Universidad Complutense de Madrid; FLACSO Argentina; la Universidad Federal de Paraná; el European Observatory on Infringements of Intellectual Property Rights, IP in the Digital World \& Awareness Service, EUIPO; el Centro Regional para el Fomento del Libro en América Latina y el Caribe (CERLALCUNESCO); la Universidad Externado de Colombia; Google Copyright Counsel de Portugal y el Instituto de Autor de España.

Con este Seminario, la OEI y la Universidad de Alicante y su Cátedra Iberoamericana de Cultura Digital apostaron por formar en cultura digital como instrumento para poner en valor y promover la cultura iberoamericana y las posibilidades que ofrece.

\section{BIBLIOGRAFÍA}

- Instituto Cervantes (2021) El español: una lengua viva. Informe 2021. Disponible en: https://cvc.cervantes.es/lengua/ anuario/anuario_21/informes_ic/p05.htm [Consulta: 16/12/2021]

- Albuquerque y Esperança, A.J. (2010) El valor económico del portugués: lengua de conocimiento con influencia global (ARI). Real Instituto El Cano, 30 agosto de 2010. Disponible en: http://www.realinstitutoelcano.org/wps/portal/rielcano_es/ contenido?WCM_GLOBAL_CONTEXT=/elcano/elcano_es/ zonas_es/lengua+y+cultura/ari127-2010 [Consulta: 16/12/2021] 